\title{
Effect of Vibration and Shock on Unsaturated Standard Cells
}

\author{
Ralph J. Brodd and Woodward G. Eicke, Jr.
}

\begin{abstract}
(January 23, 1962)
The effect of mechanical vibration and shock on a group of 500-ohm unsaturated standard cells has been investigated. Vibration studies were conducted at frequencies of $10,20,30,50,70,100,200,500$, and 1,000 cycles per second with accelerations of 1, 2, 5, 7, and 10 gravities $(g)$. The shock studies were conducted with shock durations of $6.2,11$, and 18 milliseconds and shock accelerations of $10,20,30$, and $40 \mathrm{~g}$. The vibration of the cells produced an alternating component in the emf of the cells at the same frequency as the frequency of vibration and dependent on the magnitude of the acceleration. At low frequencies distortions and harmonics were found in the alternating component of the cell emf. In addition to the alternating component a shift in the cell emf was also observed during vibration which depended on the magnitude of the acceleration and the frequency of vibration. At all frequencies and at $1 \mathrm{~g}$ acceleration the cell emf was within the 0.01 percent limit of precision usually assigned to unsaturated cells. A large transient emf often exceeding one millivolt was observed during the shock studies. However, the steady emf of the cell did not change more than two microvolts in the shock study. Neither vibration nor shock had a lasting effect on the emf of the unsaturated cells. Possible sources for the observed transient effects are considered. A method for mounting the standard cells so that mechanical vibration or shock is efficiently transmitted to the test cell is described.
\end{abstract}

\section{Introduction}

The increased demands of science and technology have continually forced the extension of the accuracy and precision of the standards of physical measurement. Some of these standards such as the standard sample series of chemical composition are unaffected by vibration or shock. Other standards such as the standard cell for voltage reference may be influenced by mechanical vibration or shock. The standard cell is considered to be a relatively delicate standard since glass is used for container construction, and the electrodes, being partially liquid, are not structurally stable. The operational procedures using standard cells, whether the standardization of a potentiometer in a laboratory or the transportation of the cells from one laboratory to another for intercomparison with other standard cells, subject the standard cells to mechanical shocks and/or vibration of varying intensity. The availability of information of a quantitative nature on the effect of shock and vibration on the operating characteristics of the standard cell would permit more effective use of the cells. Also, knowledge of the stability of the standard cells in adverse environment should permit an evaluation of the reliability of the standard cell as a voltage reference source. It is the purpose of this paper to report the results of a preliminary investigation of the effect of mechanical shock and vibration on the stability of the emf of $500-\mathrm{ohm}$ unsaturated standard cells.

\section{Experimental Procedure}

\subsection{Standard Cell Mounting}

Two 500-ohm unsaturated standard cells from each of two manufacturers were used in this study.
The cells were mounted on a one-piece fixture with the aid of an epoxy resin. A typical cell mounting is shown in figure 1. The fixture was fabricated from a solid piece of $4 \mathrm{in}$. $\times 4 \mathrm{in}$. aluminum block. The details of the fixture are shown in figure 2 . Three aluminum sides were placed around surface $A$ of the fixture to form a mold, so that with surface $A$ in a horizontal position, the three sides, surface $A$, and surface $B$ formed a mold in which the cells and the mounting screws could be potted with epoxy resin. The inside of the cavity was carefully

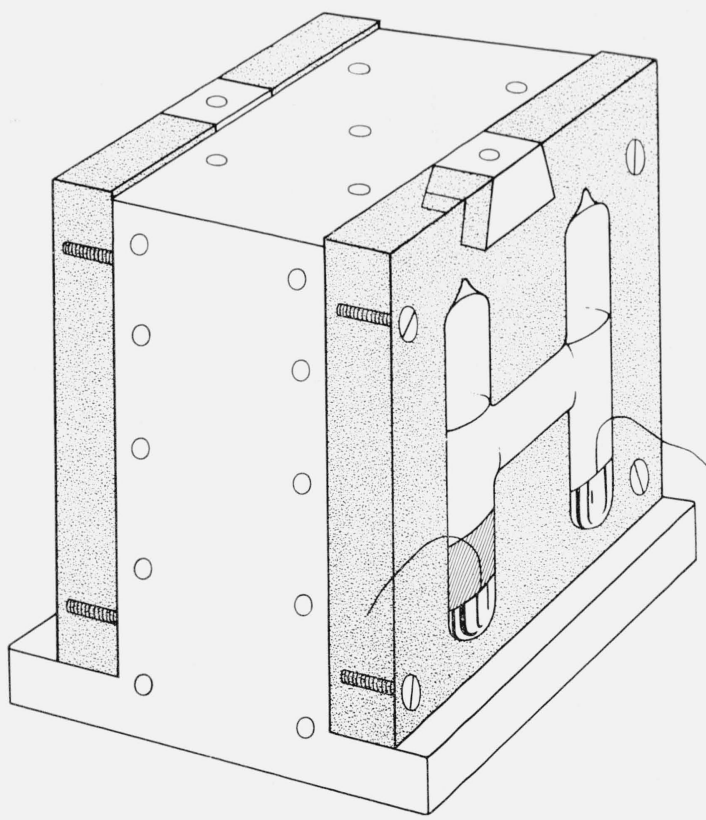

FIgure 1. Fixture for vibration and shock studies with test cells mounted. 

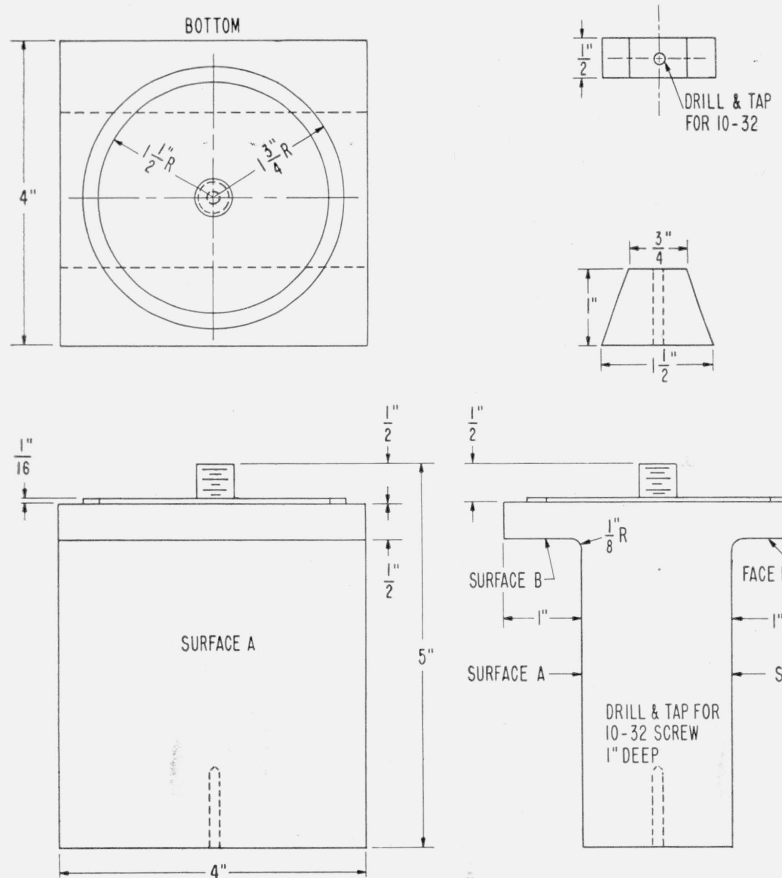

Figure 2. Details of cell mounting fixture.

coated with silicone grease for later removal of the sides and eventually of the cells from the fixture. A small aluminum block for mounting the acceleration pickup was bolted to the molding jig so that there was a $1 / 32$-in. clearance between the acceleration mount and surface $A$ of the fixture. The screws and the test cell were positioned in the mold and the epoxy resin ${ }^{1}$ was poured into the mold to

\footnotetext{
1 The epoxy resin was prepared immediately before use from Epon 815 resin and di-ethylaminopropylamine catalyst in the ratio of $100 \mathrm{~g}$ of resin to $7.5 \mathrm{~g}$ of catalyst.
}

a depth of about $5 / 8$ in. The test cell was almost completely covered with the resin. The resin cured slowly. The temperature of the resin and the test cell never rose above $35^{\circ} \mathrm{C}$ during the curing process. After the resin had set, the fixture was turned over and the molding procedure was repeated on the opposite face of the fixture. Two test cells, one from each manufacturer, were mounted on the fixture. This type of cell mounting proved to be rugged and a satisfactory means of mounting cells for the environmental studies.

\subsection{Vibration and Shock}

The vibration studies on the unsaturated standard cells were conducted using a Calidyne Model 75B vibrator. Figure 3 illustrates the experimental arrangement for the vibration study. The vibrator was driven with an oscillator and a power amplifier. The frequency of the oscillator was monitored with an electronic counter. The aluminum standard cell fixture was mounted on the vibrator table with the center line of the fixture in the center of the vibrator table. The test cells were always in an upright position during this study. An accelerometer was mounted at the center of the fixture. Accelerometers were mounted also on each of the acceleration mounts above the test cells. The output of the accelerometers was monitored with a cathode follower network and a suitable voltmeter.

The test cells were subjected to vibrations of $10,20,30,50,70,100,200,500$, and $1,000 \mathrm{c} / \mathrm{s}$. At each frequency the cells were subjected to accelerations of $1,2,5,7$, and $10 \mathrm{~g}$. Before and after the vibration program at each frequency, the vibrator was set to $1,000 \mathrm{c} / \mathrm{s}$ and $5 \mathrm{~g}$ acceleration in order to check the reproduciblity of the vibrator and the test cells. At the low frequencies the

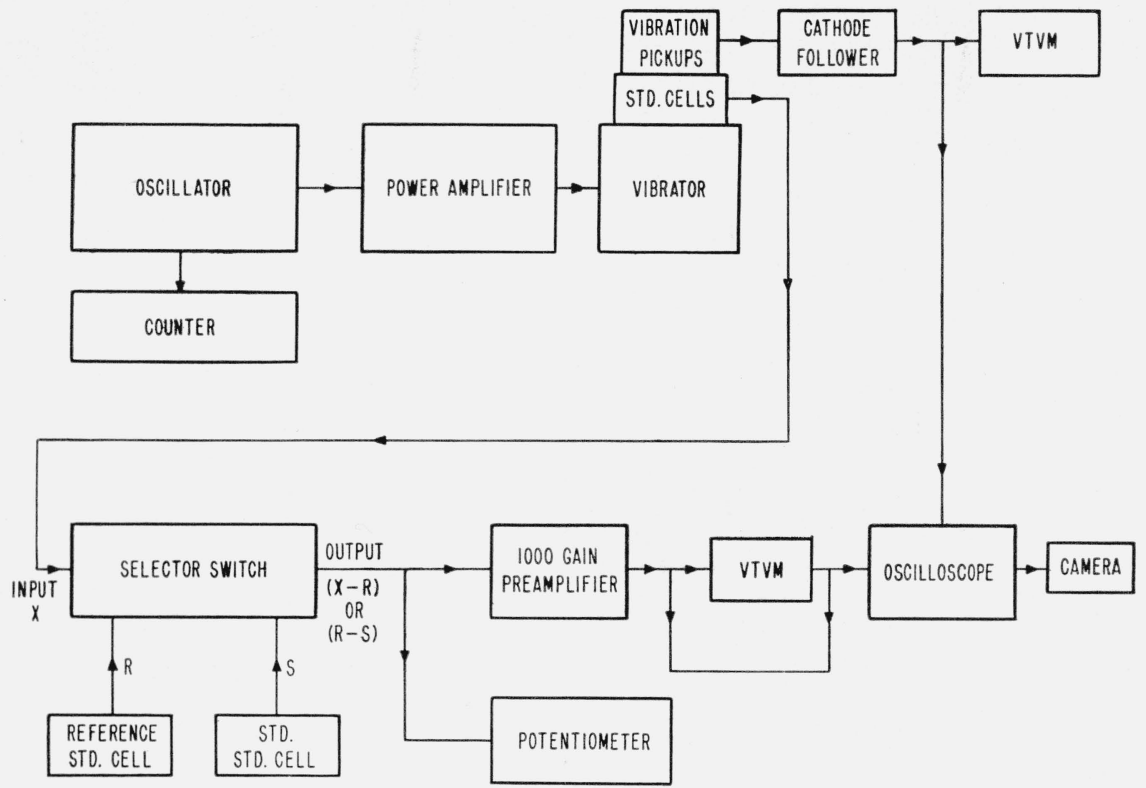

FIGURE 3. Block diagram of experimental arrangement used to study the effect of vibration on standard cells. 
maximum acceleration was limited by the ability of the vibrator to produce an undistorted sinusoidal vibration. The accelerometer on the center of the fixture was used to set the amplitude of the vibrator. The acceleration on the center of the fixture and the accelerations on the mounting block above each test cell were recorded simultaneously. The test cells were mounted on the vibrator the night before the test. The d-c power to the vibrator was activated about $5 \mathrm{hr}$ before the test was begun to insure thermal equilibrium of the vibrator table and the test cells. During the test the room temperature was $25{ }^{\circ} \mathrm{C}$ and the test cell temperature was $35{ }^{\circ} \mathrm{C}$.

The shock investigations were conducted using a Barry 20 V.I. shock machine. The schematic of the experimental setup is shown in figure 3 with the shock machine replacing the oscillator, electronic counter, power amplifier, and vibrator. The test cell mounting and the positioning of the acceleration pickups were identical for both the shock and vibration studies. The temperature of the cells during shock studies was $25^{\circ} \mathrm{C}$. The output of the center pickup was used to monitor the character of the shock. The four test cells were subjected to shocks of approximately $6.2,11$, and 18 msec duration and to forces of approximately $10,20,30$, and $40 \mathrm{~g}$. The cells were subjected to each shock twice. This served to check the reproducibility of the shock and of the change in $d-c$ emf of the test cells as a result of the shock. The magnitude and duration of the shock was determined by varying the height from which the cells were dropped and the arresting means of the shock machine.

\subsection{Electrical Measurements}

The details of the circuit used for the electrical measurements are shown in figure 4 . The same circuit was used for both the vibration and shock studies. Shielded leads were used throughout and all switches and standard cells except the test cells were shielded. The fixture and vibrator or shock table were bonded electrically and were grounded to the oscilloscope. The oscilloscope was used as the point of grounding for the entire circuit in figure 4 as well as and for all electrically powered instruments used in the study. All the electrical instruments were plugged into a common source. The leads from the test cells were connected to the selector switch. A common negative was used for both cells. Although the negative lead of the test cells was at ground potential, a separate negative lead was run from the cells to the selector switch and the connection to ground was made at the selector switch. The output of the test cells, $X_{1}$ or $X_{2}$, was compared individually with the reference cell, $R$. The difference in emf between the test cells and the reference cell was determined with a Leeds and Northrop Type K-3 potentiometer. A Kintel Model 204A

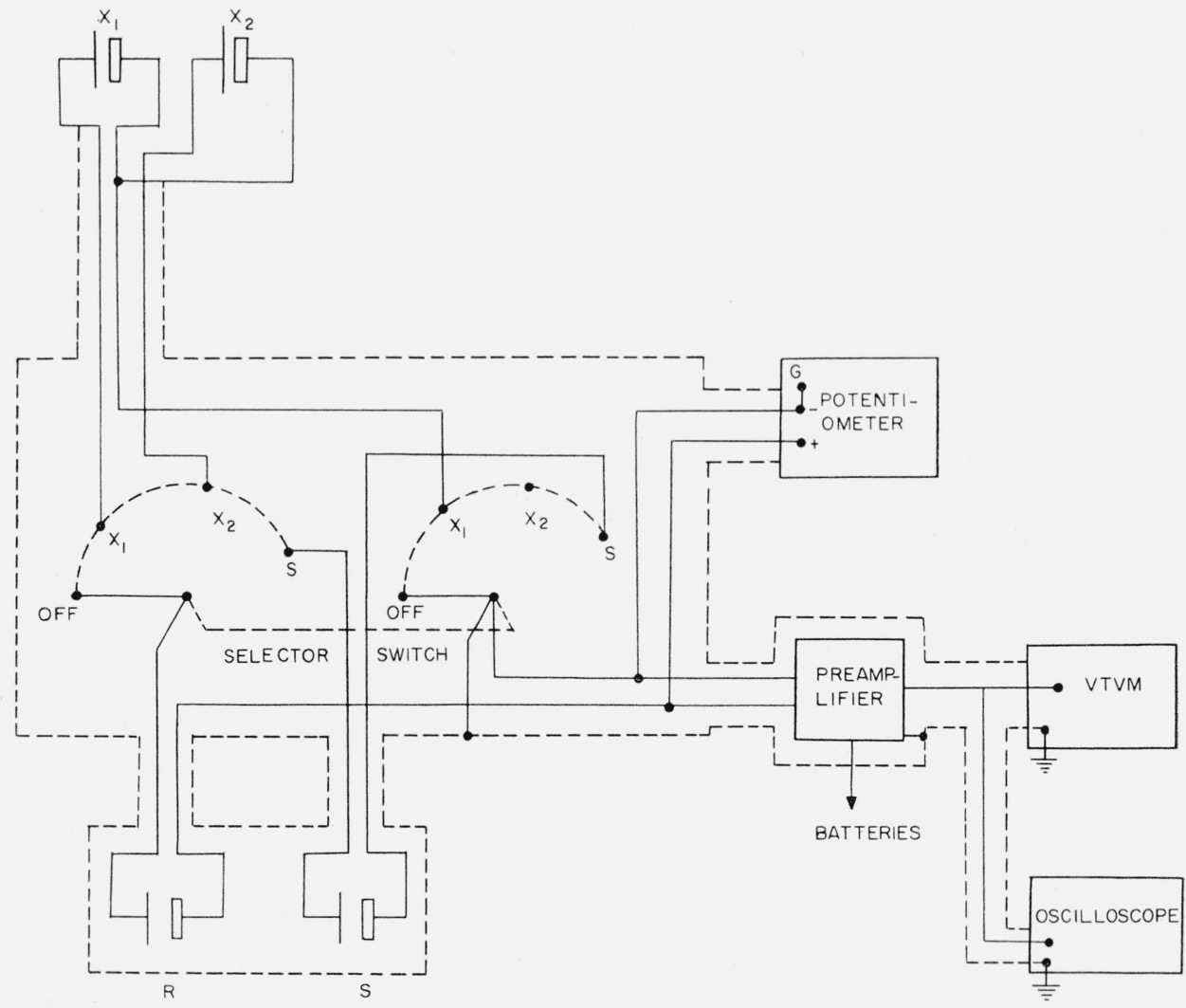

Figure 4. Schematic diagram of electrical circuit used to study the effect of vibration on standard cells. 
electronic galvanometer was used as a null indicator. The emf of the reference cell was checked periodically against the emf of the standard cell, $S$. $R$ and $S$ were placed in a copper box which provided both electrical and thermal shielding. Both $S$ and $R$ were new unsaturated cells which were known to have an excellent short-term stability.

The a-c signal from $X-R$ was amplified by a calibrated 1,000 gain Tektronix Model 122 preamplifier. The amplifier had a pass band of 0.8 cycle to 40 $\mathrm{kc} / \mathrm{s}$ and an input impedance of $10 \mathrm{megs}$ paralleled by $50 \mathrm{pf}$. The amplified signal was displayed on a Model 533 Tektronix oscilloscope equipped with a Type CA preamplifier and was also measured with a HewlettPackard Model $400 \mathrm{H}$ voltmeter. The latter instrument responded to the average a-c voltage. The a-c noise level as measured with the voltmeter was always less than $3 \mu \mathrm{v}$ or essentially the noise level of the preamplifier. The signal from the accelerometer was also displayed on the oscilloscope simultaneously with the a-c output of the test cell. For each frequency and acceleration studied, a photograph of the oscilloscope traces was made and reading of the volt meter was taken at the same time. A permanent record of the test cell output and the ouptut from the accelerometer was thus obtained.

After the vibration tests were conducted, the test cells were replaced by a dummy load of equivalent resistance and loop area. The field of the vibrator was activated at the frequencies encountered in this study, and the dummy load, used as a probe, was moved about on the vibrator table as well as under the vibrator table and in the space surrounding the test cells. The effects of the magnetic field from the vibrator detected in this fashion were less than the noise level in the circuit.

\section{Results and Discussion}

\subsection{Cell Mounting Evaluation}

An important aspect of this study was to estimate the efficiency of transmission of the vibration force from the aluminum block to the test cell. In this evaluation the center accelerometer was used as the reference for the acceleration. The accelerometer mounted in the epoxy resin above the standard cell was used to indicate the acceleration on the standard cell. Although there is a difference in weight and binding of the resin to the cell and acceleration mount, the acceleration determined by the accelerometer above the cell should be a good indication of the acceleration on the test cell. The acceleration measured by the pickup on the epoxy resin is plotted as the ordinate and the acceleration measured by the pickup on the aluminum block is plotted as the abscissa in figure 5. If there is ideal transmission of the force from the aluminum block to the standard cell, the slope of the plot should be 1, corresponding to the solid line drawn on the figure. In order to ascertain whether or not this condition was met, the data of figure 5 were fitted with the best straight line using the IBM 704 computer. The slope, intercept and their standard deviations were com-

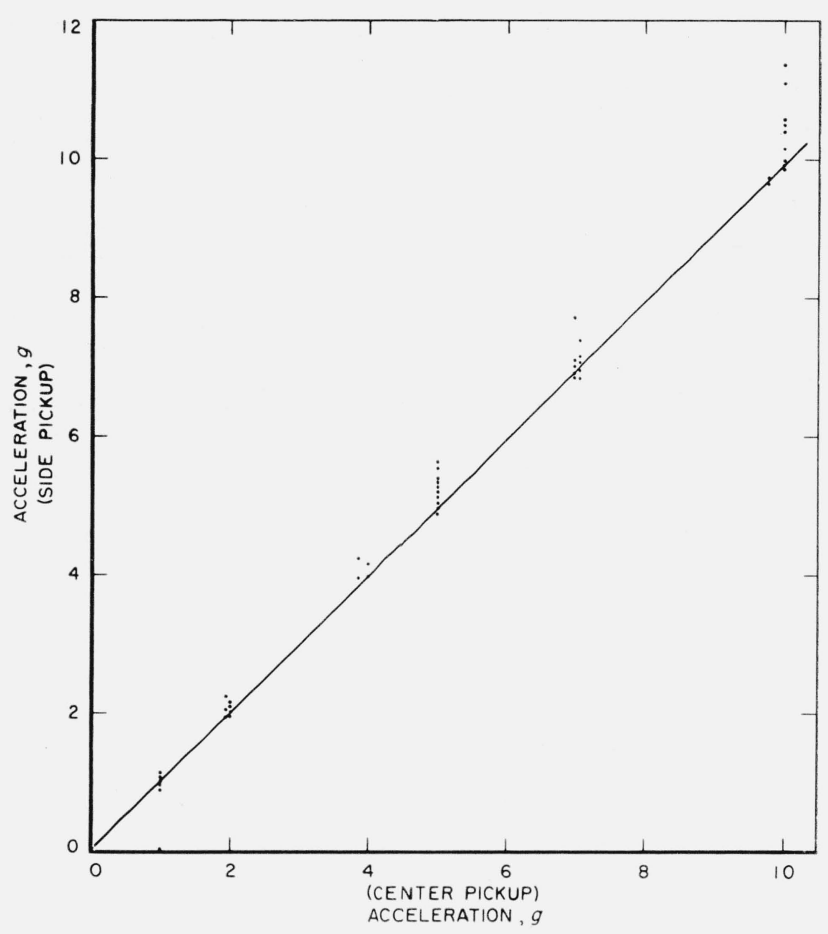

Figure 5. Correlation between center pickup and pickups mounted over the test cells.

puted for each cell. The slopes for the four cells were calculated to be $0.999,1.035,1.010$, and 1.050 and the pooled standard deviation of the slopes was 0.0099 . If the difference between the center pickup and the pickup above a particular cell was due entirely to random variations, one would expect the slope of the line for any given cell to be $1.00 \pm 0.02$ (using the $95 \%$ confidence limit). It can be seen that two of the cells fall into this interval while two do not. It must therefore be concluded that there is some variability in the mounting technique. The worst deviation from the ideal noted is no greater than 7 percent. However, as will be seen later, this deviation is small compared to the overall variability of the results.

Measurements of the phase difference between accelerometers on the aluminum block and on the resin mount indicated that the two outputs from the accelerometers were approximately in phase. The significant deviations from expected behavior (in fig. 5) are always in the direction of a larger acceleration on the resin than on the aluminum block. If the resin has an elastic modulus that is smaller than the aluminum, deviations from expected behavior should be thus in the direction of larger vibration amplitude with a corresponding larger acceleration. The smaller elastic modulus of the resin should also cause the output of the resin mounted accelerometer to lag behind the aluminum block pickup but the phase measurements were not sufficiently precise to confirm this. It may, therefore, be concluded that the force is transmitted with good efficiency from the vibrator to the test cell. 


\subsection{Reproducibility}

In order to estimate the reproducibility of the individual cells and to serve as a control, the cells were subjected to a vibration of $1,000 \mathrm{c} / \mathrm{s}$ with a maximum force of $5 \mathrm{~g}$ before and after the vibration study at each frequency. The results of these checks are presented in table 1 for the four cells. ${ }^{2}$ The standard deviation, $s_{m}$, is reported both in microvolts and as a percentage of the mean. The latter standard deviations for the four cells have been pooled to give an overall estimate of the reproducibility for both the a-c and d-c measurements; the pooled estimates of the reproducibility are 8.4 and 32.3 percent, respectively. Since it was possible to set the frequency and acceleration with a precision of better than 1 percent, the cause for the large standard deviation of the mean reported above must reside within the test cells themselves. Only one cell showed a systematic variation in the repeat tests at $1,000 \mathrm{c} / \mathrm{s}$ and $5 \mathrm{~g}$. In this case the a-c output decreased steadily as the vibration studies continued. The other cells showed no such systematic variation.

TABLE 1. Reproducibility of the measurements at $1,000 \mathrm{c} / \mathrm{s}$ and $5 \mathrm{~g}$

\begin{tabular}{|c|c|c|c|c|c|c|}
\hline \multirow{2}{*}{ Cell No. } & \multicolumn{3}{|c|}{$\mathrm{AC}^{*}$} & \multicolumn{3}{|c|}{$\mathrm{DC}$} \\
\hline & Mean & $s_{m}$ & $s_{m}$ & Mean & $s_{m}$ & $s_{m}$ \\
\hline $\begin{array}{l}1 \\
2 \\
4 \\
6\end{array}$ & $\begin{array}{r}\mu v \\
927 \\
207 \\
207 \\
84\end{array}$ & $\begin{array}{c}\mu v \\
40 \\
25 \\
27 \\
3.5\end{array}$ & $\begin{array}{c}\% \\
3.88 \\
10.87 \\
11.73 \\
3.80\end{array}$ & $\begin{array}{r}\mu v \\
-50.1 \\
-9.4 \\
-8.7 \\
-9.7\end{array}$ & $\begin{array}{r}\mu v \\
9.3 \\
3.7 \\
3.7 \\
2.1\end{array}$ & $\begin{array}{c}\% \\
18.56 \\
39.36 \\
42.52 \\
21.64\end{array}$ \\
\hline \multicolumn{3}{|c|}{ Pooled $s_{m-\ldots}$} & 8.44 & & & 32.3 \\
\hline
\end{tabular}

*See footnote 2.

\subsection{Results of Vibration Studies}

The arithmetic means of the a-c and d-c outputs of the test cells during the vibration studies are reported in table 2 along with the standard deviation, $s_{m}$, for both the a-c and d-c measurements. The standard deviation expressed as percent of the mean was calculated using the formula:

$$
s_{m}=\frac{0.243 w}{M} \times 100
$$

where $w$ is the range and $M$ is the mean a-c or d-c output of the four cells. The d-c results below 100 $\mathrm{c} / \mathrm{s}$ are omitted since the null detector used with the potentiometer was sensitive to an a-c input at low frequency. Typical oscilloscope photographs of the output from the test cells during vibration is shown in figure 6 along with the output from the accel-

\footnotetext{
${ }^{2}$ All a-c measurements are reported as average voltages.
}

erometer. At low frequency some of the waveforms produced by the vibrator were not truly sinusoidal. However, the results, in these instances, may be used to estimate the magnitude of the effect of vibration on the test cell emf. It is significant that the d-c effects are always in the direction to produce a decrease in the cell emf during vibration.

The standard deviations in table 2 are quite large. In view of the fact that the reproducibility studies at $1,000 \mathrm{c} / \mathrm{s}$ and $5 \mathrm{~g}$ gave standard deviations substantially less than those found in table 2 for both the a-c and d-c results, it must be concluded that a large portion of the variability in the results must be ascribed to the individual cells. Although it is not possible on the basis of two samples to draw firm conclusions, there does not appear to be a marked difference in the transient output of cells from the two manufacturers.

TABLE 2. Mean average a-c output and $d$-c change for four 500-ohm unsaturated standard cells

\begin{tabular}{|c|c|c|c|c|c|c|c|c|c|c|}
\hline \multirow{2}{*}{ Frequency } & \multicolumn{2}{|c|}{$1 g$} & \multicolumn{2}{|c|}{$2 g$} & \multicolumn{2}{|c|}{$5 g$} & \multicolumn{2}{|c|}{$7 g$} & \multicolumn{2}{|c|}{$10 g$} \\
\hline & Mean & $s_{m}$ & Mean & $s_{m}$ & Mean & $s_{m}$ & Mean & $s_{m}$ & Mean & $s_{m}$ \\
\hline
\end{tabular}

\begin{tabular}{|c|c|c|c|c|c|c|c|c|c|c|}
\hline \multicolumn{11}{|c|}{$\mathrm{AC}$} \\
\hline${ }_{10^{c / s}}^{c / s}$ & $\mu v$ & $\%$ & $\mu v$ & $\%$ & $\mu v$ & $\%$ & $\mu v$ & $\%$ & $\mu v$ & $\%$ \\
\hline 20 & $\begin{array}{l}1010 \\
1339\end{array}$ & 80.6 & 3632 & 57.2 & *3994 & 69.4 & & & & \\
\hline 30 & 394 & 52.7 & 2021 & 50.8 & 5312 & 59.3 & 5936 & 58.4 & & \\
\hline 50 & 316 & 70.6 & 547 & 37.2 & 2583 & 47. 0 & 4417 & 51.0 & 9900 & 66.4 \\
\hline 70 & 139 & 52.3 & 309 & 41. 1 & 1500 & 49.5 & 1975 & 48.7 & 4725 & 39.6 \\
\hline 100 & 56 & 61. 6 & 152 & 49.7 & 592 & 28. 9 & 1020 & 21.7 & 1808 & 30.9 \\
\hline 200 & 32 & 54. 3 & 87 & 30.9 & 310 & 28. 6 & 443 & 23.4 & 729 & 20.1 \\
\hline 500 & 14 & 18.8 & 33 & 5.4 & 128 & 17. 2 & 184 & 23.5 & 366 & 6.0 \\
\hline 1000 & 24 & 51.8 & 66 & 57.5 & 321 & 62.5 & 496 & 55.4 & 795 & 50.3 \\
\hline \multicolumn{11}{|c|}{$\mathrm{DC}$} \\
\hline 100 & -13 & 48.5 & -18 & 67.8 & -135 & 54.8 & -192 & 56.2 & -206 & 141.7 \\
\hline 200 & -6 & 80.0 & -17 & 57. 0 & -39 & 43. 6 & -61 & 31.8 & -146 & 52.3 \\
\hline 500 & -10 & 48. 0 & -14 & 57.1 & -22 & 45.4 & -42 & 39.3 & -68 & 49.0 \\
\hline 1000 & -3 & 96.7 & -6 & 41. 7 & -25 & 68.0 & -48 & 61. 4 & -79 & 70.9 \\
\hline
\end{tabular}

Note: For the de only the pooled $s_{m}$ is 65.0 percent.

*4 g.

At low frequencies visual observations of the test cells often revealed the presence of mercury drops suspended above the electrodes and/or the septa. At approximately $30 \mathrm{c} / \mathrm{s}$ ofttimes a large drop of mercury would rise from the amalgam in a formation resembling a toadstool. At other times ripples would appear on the amalgam surface. Whenever the drops or ripples appeared both the a-c and d-c outputs from the cells were erratic. At the low frequencies harmonics and distortions were usually found in the photographs of the cell output. The a-c and d-c output of the cell appeared instantaneously when the vibration started. The a-c and d-c output also disappeared instantly when the vibration ceased. In some instances the d-c change would be very rapid in the initial moments of vibration then build up slightly in an exponential manner for 2 or $3 \mathrm{~min}$. When the vibration stopped, the $\mathrm{d}$-c emf would decay in the same fashion as it built up. 

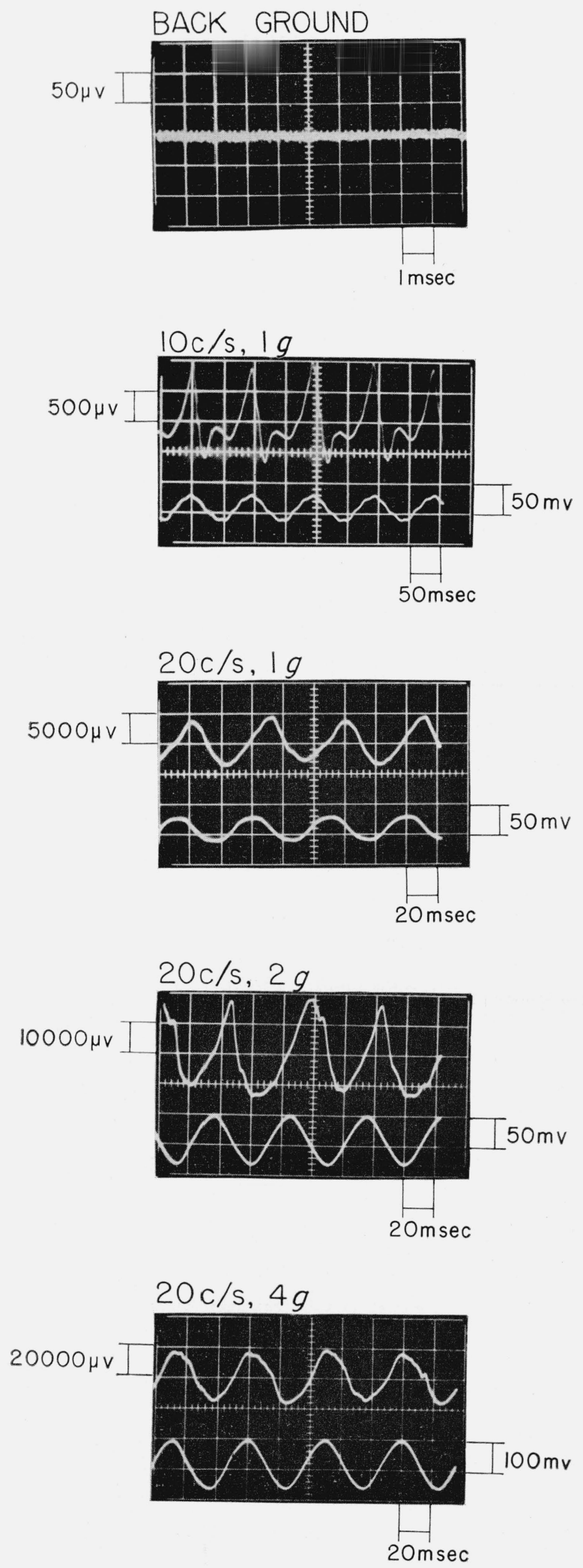
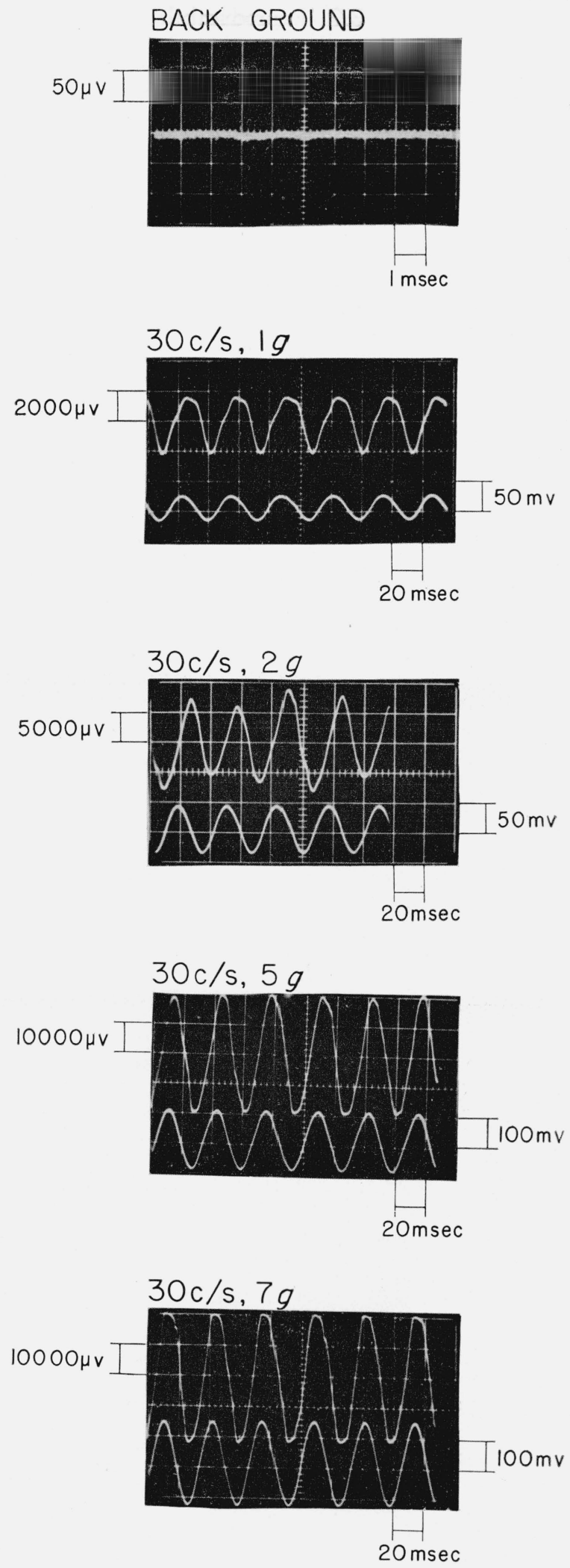

FIGURE 6. Oscilloscope trace of the a-c output and acceleration pickup at various frequencies and applied forces. 

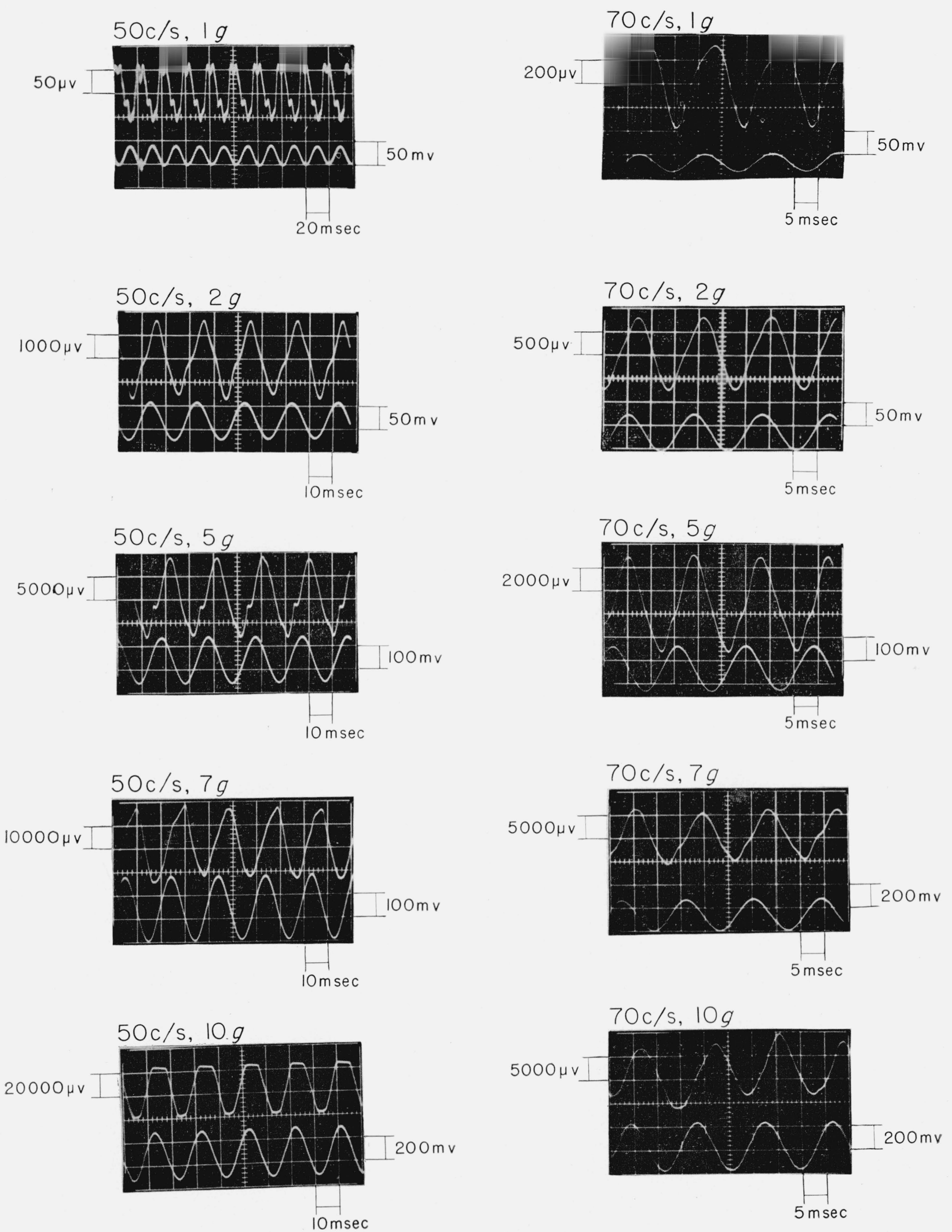

FIGURE 6. Oscilloscope trace of the a-c output and acceleration pickup at various frequencies and applied force-Continued. 

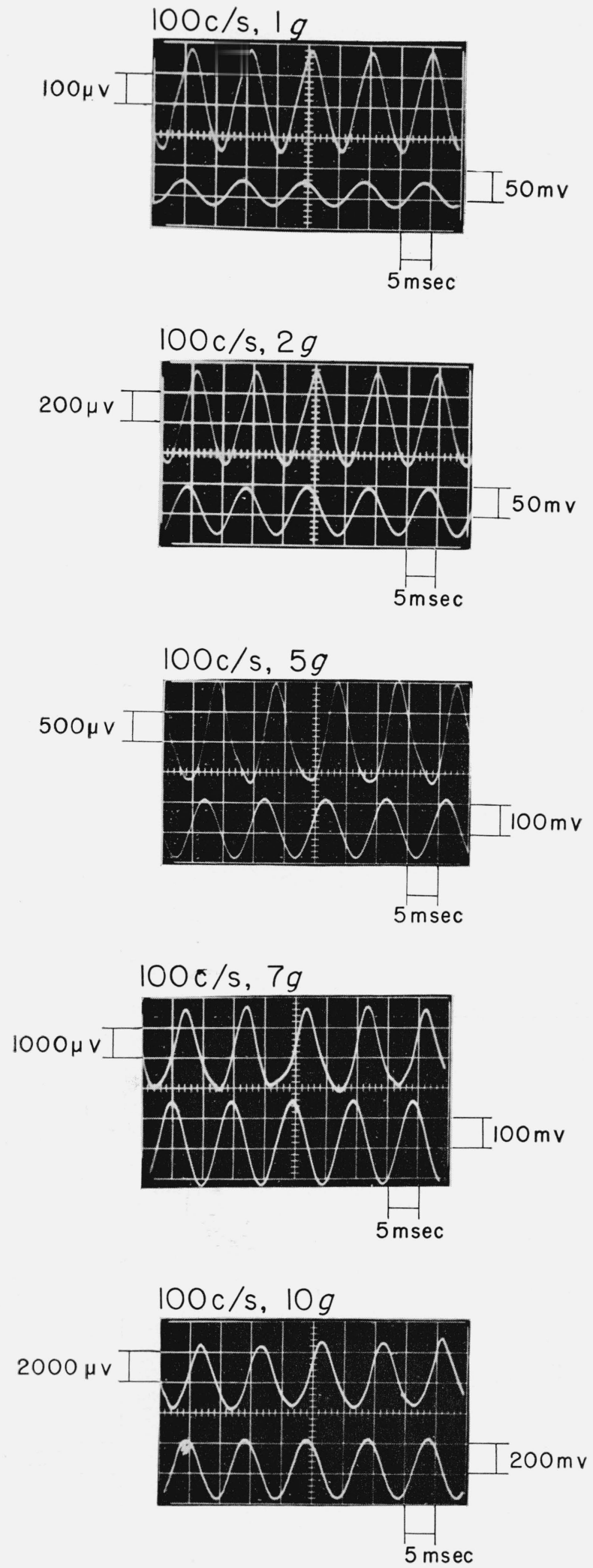
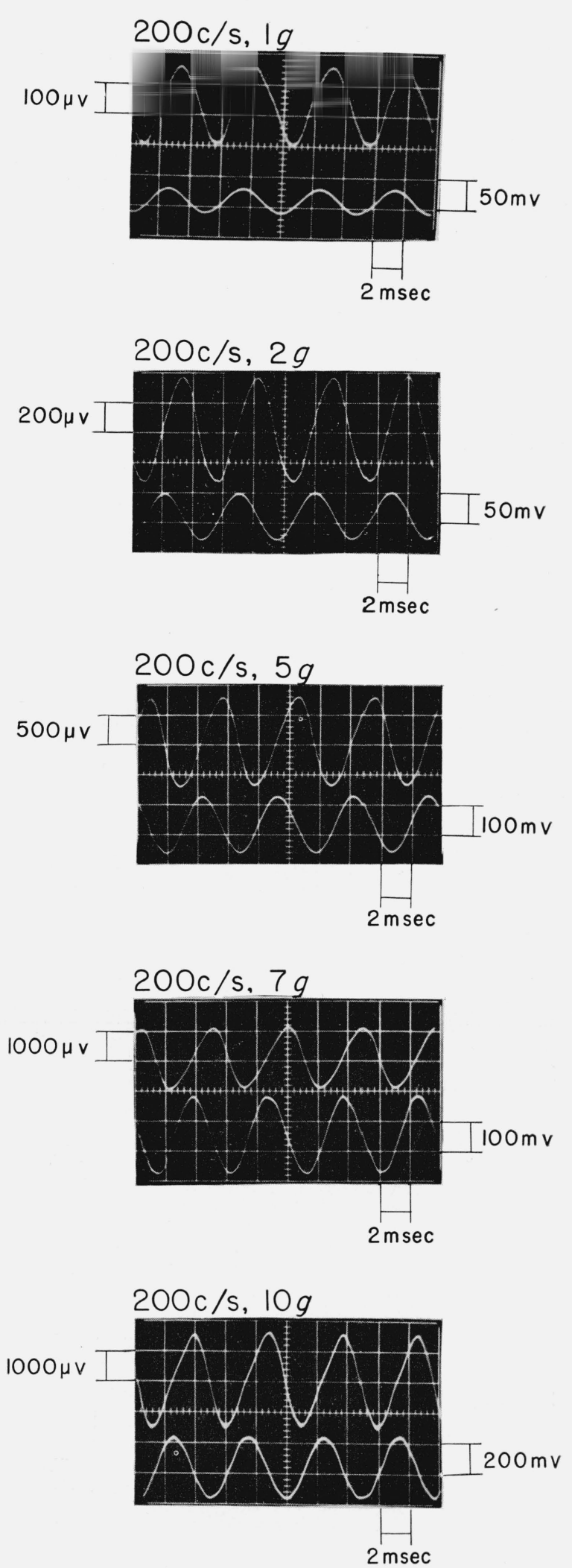

FIGURE 6. Oscilloscope trace of the a-c output and acceleration pickup at various frequencies and applied force-Continued. 

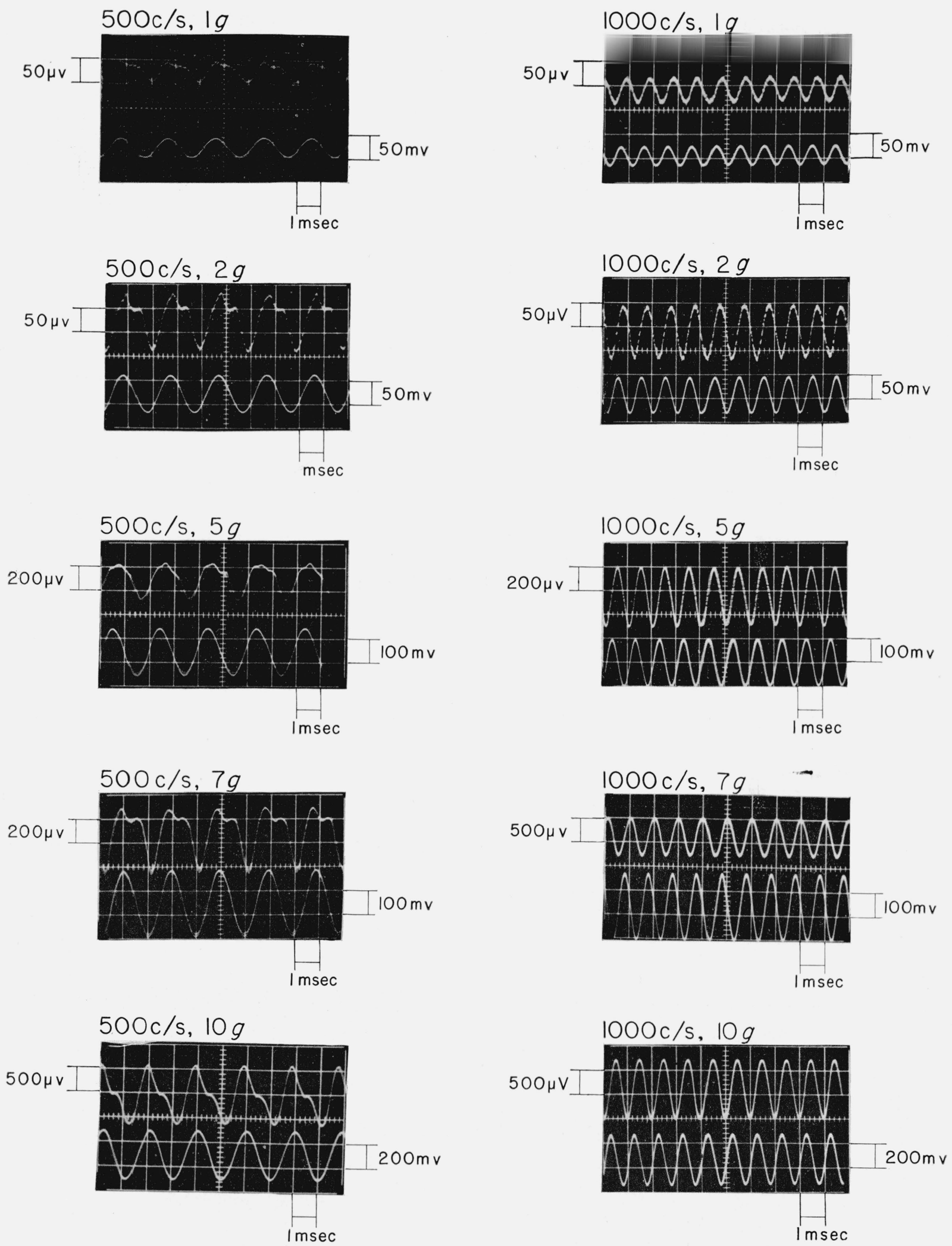

FIgURE 6. Oscilloscope trace of the a-c output and acceleration pickup at various frequencies and applied force-Continued. $628208-62--2$ 


\subsection{Results of Shock}

The results of the shock investigations are given in table 3 . The standard deviations were calculated using the formula given in eq (1). Photographs typical of the actual cell output and the accelerometer output are displayed in figure 7 . The shock as determined by the accelerometer was reproducible to \pm 10 percent. Since the standard deviations of the cell output are considerably larger than the reproducibility of the shock machine, it must be concluded that variations in the individual cells are responsible for the variability in the results. Sometimes a transient would be observed at a considerable time after the cell had received a shock. A close observation of the cell after shock revealed that these transients were the results of the coalescing of small mercury drops into larger, more stable drops. When the cell was shocked, the large drop was broken into several smaller drops. This process of dispersion and coalescence of the mercury drops could be repeated endlessly. Cells which contained large amounts of free mercury produced larger transient outputs than cells without free mercury drops. A similar phenomenon has been reported previously [1]. ${ }^{3}$

TABLE 3. Maximum transient output and the standard deviation

\begin{tabular}{|c|c|c|c|c|c|c|c|c|}
\hline \multirow{3}{*}{$\begin{array}{l}\text { Shock } \\
\text { duration }\end{array}$} & \multicolumn{8}{|c|}{ Nominal shock, g } \\
\hline & \multicolumn{2}{|c|}{10} & \multicolumn{2}{|c|}{20} & \multicolumn{2}{|c|}{30} & \multicolumn{2}{|c|}{40} \\
\hline & $\begin{array}{l}\text { Mean } \\
\text { output }\end{array}$ & $s_{m}$ & $\begin{array}{l}\text { Mean } \\
\text { output }\end{array}$ & $s_{m}$ & $\begin{array}{l}\text { Mean } \\
\text { output }\end{array}$ & $s_{m}$ & $\begin{array}{l}\text { Mean } \\
\text { output }\end{array}$ & $s_{m}$ \\
\hline 6.2 $\mathrm{msec}$ & $\mu v$ & $\%$ & $\mu v$ & $\%$ & $\begin{array}{c}\mu v \\
24000\end{array}$ & $\begin{array}{c}\% \\
45.8\end{array}$ & $\mu v$ & $\%$ \\
\hline 11 & 4425 & 34.0 & 13050 & 40.8 & 21500 & 25.2 & 31000 & 19.4 \\
\hline $18 \ldots$ & 4200 & 39.0 & 12500 & 34.8 & 16625 & 33.0 & & -...... \\
\hline
\end{tabular}

Pooled $s_{m}=34.9 \%$.

The d-c emf of the test cells was remarkably constant during the shock studies. The change in d-c emf for all cells in this study did not exceed $2 \mu \mathrm{v}$. This variation is slightly larger than the ability of the potentiometer to determine the difference in emf between the test cell and the reference cell. The overall precision of the $\mathrm{d}$-c measurement for the vibration and the shock was $\pm 1 \mu \mathrm{v}$.

\subsection{Transient A-C EMF Effects}

There are four possible sources of the transient a-c emf effects observed when the test cells were subjected to vibration or shock. The only source which appears to account for the observations is the so-called "U-effect," or the electrokinetic properties of interfaces. Other possible sources of the observed transient are the effect of pressure on the cell reaction, the effect of pressure on the compression of the electrical double layer at a mercury surface, and the effect of temperature on the cell emf as a result of heating of the cells during vibration and shock.

\footnotetext{
${ }^{3}$ Figures in brackets indicate the literature references at the end of this paper
}

The effect of pressure on the cell emf, $E$, is given by

$$
d(\Delta G)=\Delta \bar{V}_{m} d P-\Delta S d T=-n \mathbf{F} d E
$$

where $\Delta G$ is the change in free energy of the cell reaction, $\Delta \bar{V}_{m}$ is the change in molar volume as a result of the cell reaction, $d P$ is the change in pressure, $\Delta S$ is the change in entropy for the cell reaction, $n$ is the number of electrons transferred in the cell reaction, $\mathbf{F}$ is Faraday's constant, and $d T$ is the change in temperature. The rate of change in cell emf $(\partial E / \partial P)_{T}$ with pressure at constant temperature is given by

$$
(\partial E / \partial P)_{T}=-\Delta \bar{V}_{m} / n \mathbf{F} .
$$

For the purpose of calculation the molar volume of $\mathrm{CdSO}_{4}$ (solution) was taken to be the molar volume of $\mathrm{CdSO}_{4}$ (solid), 44.440; of $\mathrm{Cd}, 13.007$; of $\mathrm{Hg}$, 14.810, of $\mathrm{Hg}_{2} \mathrm{SO}_{4}, 65.778$; and the cell reaction was taken to be

$$
\mathrm{Cd}+\mathrm{Hg}_{2} \mathrm{SO}_{4}=2 \mathrm{Hg}+\mathrm{CdSO}_{4} \text { (solution). }
$$

From these data then the influence of pressure is $(\partial E / \partial P)_{T}=2.5 \times 10^{-6} \mathrm{v} / \mathrm{atm}$ for the cell. The change in cell emf expected as a result of a $40 \mathrm{~g}$ shock assuming an average density of the material above the electrodes of $2.00 \mathrm{~g} / \mathrm{cm}^{3}$ and the height of the material above the electrodes to be $3.00 \mathrm{~cm}$, is $d E \cong 0.6 \times 10^{-6} \mathrm{v}$. The effect of pressure on the cell reaction is therefore small even at the largest acceleration encountered in this study.

The effect of pressure on the compression of the electrical double layer at the electrode-solution interface may be calculated using the equation

$$
d E_{d}=\frac{2 F}{Q} d x
$$

where $Q$ is the surface charge density on the electrodes, $F$ is the applied force, $d x$ is the change in thickness of the electrical double layer as a result of the compression by the force, and $E_{d}$ is the potential drop across the electrode solution interface. The compressibility of $\mathrm{CdSO}_{4}$ solution may be taken to be approximately $50 \times 10^{-6} \mathrm{~cm}^{3} / \mathrm{atm}$ (the compressibility of water). The thickness of the electrical double layer is approximately $5 \times 10^{-8} \mathrm{~cm}$. The change in the cell emf as a result of compression of the electrical double layer at the maximum applied force, $40 \mathrm{~g}$, is $d E \cong 0.1 \times 10^{-7} \mathrm{v}$. The effect of compression is small.

The observed transient emf may be the result of frictional heating. If it were one would expect the initial and final d-c emf's of the cells to be different on both the shock and vibration tests. They were for the most part not different. For the vibration the d-c emf immediately after shutting off the vibrator was in most instances the same as at the beginning except for a few runs in which several minutes were required for the d-c emf to stabilize during the vibration and after the vibration was 

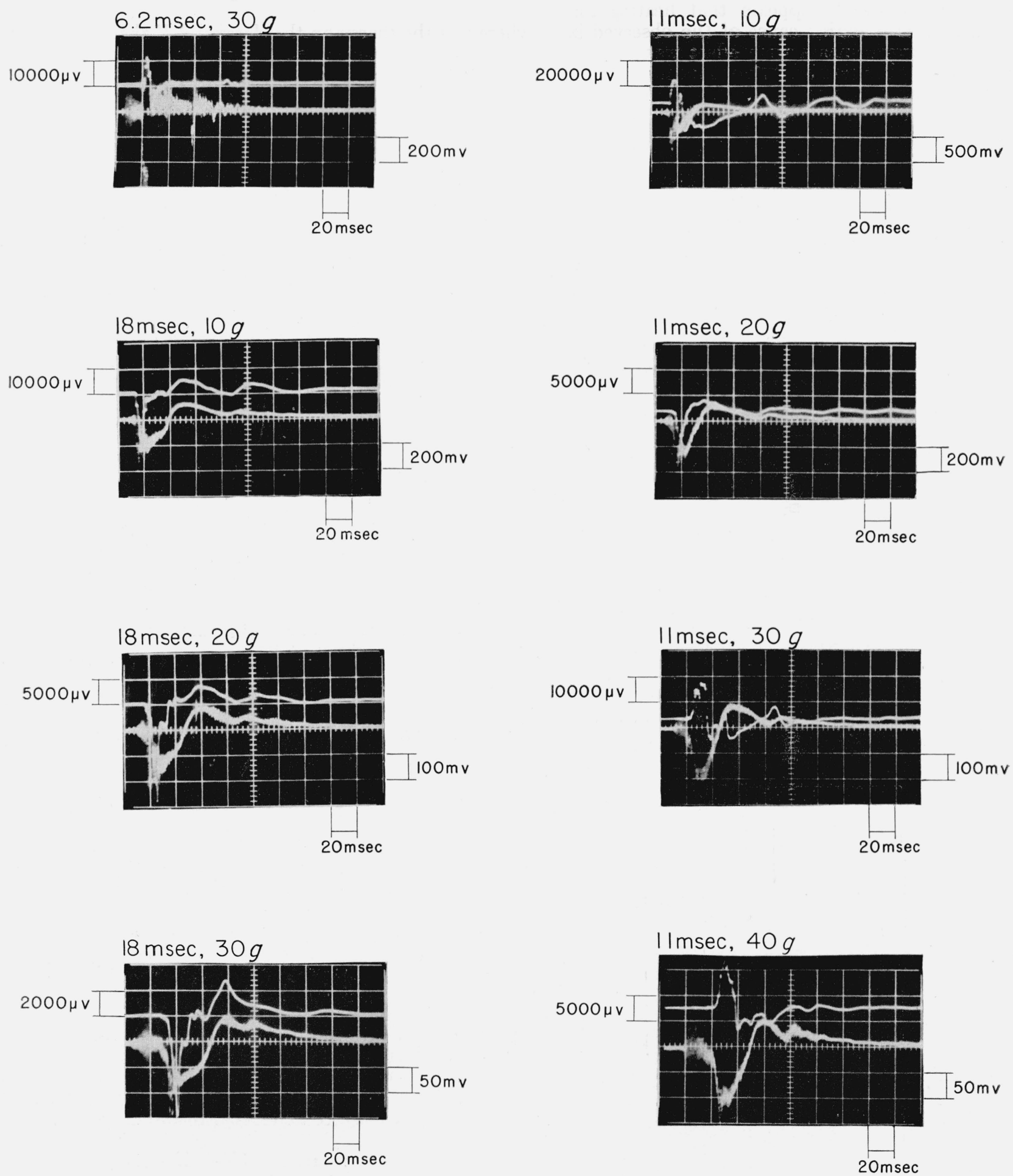

Figure 7. Oscilloscope traces of the voltage variation during the shock test. 
terminated for the cell to return to its original value. The d-c emf's immediately before and after the shock differed by less than $2 \mu v$ or within the experimental error. It appears that heating may be ruled out as a major cause of the observed behavior. However, since a time effect was observed in some cases, the possibility that local heating may occur cannot be dismissed lightly.

When the test cells are subjected to vibration or shock, the shock waves generated in the cells impinge on the surface of the electrodes. These shock waves are capable of disrupting the surface of the electrodes to form small drops of mercury. It is the formation or destruction of a mercury surface that is the underlying phenomenon of the "U-effect."

While an excellent discussion of the "U-effect" is available elsewhere, a brief account will be given for the benefit of the reader [2]. The interface between the $\mathrm{CdSO}_{4}$ solution and the mercury surface in an idealized form may be considered to be equivalent to a series combination of a capacitor and a resistor with a source of potential difference $\left(E_{d}\right)$ as shown in figure 8.

The capacitance of the interface $c$ is given by

$$
c=a / 4 \pi x=C_{0}(1+\rho a)
$$

where $C_{0}=\left(\epsilon A_{0} / 4 \pi x\right), a=A_{0}(1+\rho a), x$ is the thickness of the electrical double layer, $\epsilon$ is the effective dielectric constant of the capacitor, $a$ is the area of the electrode-solution interface in terms of $A_{0}$, the area at rest, and $\rho$ is a periodic function representing the mechanical vibration of the interface. In the section above an approximate calculation revealed that the thickness of the electrical double layer, $x$, did not change appreciably as a result of the vibration or shocks encountered in this study. If this approximation is not valid, a term representing the periodic function of $x$ must be included in eq (6).

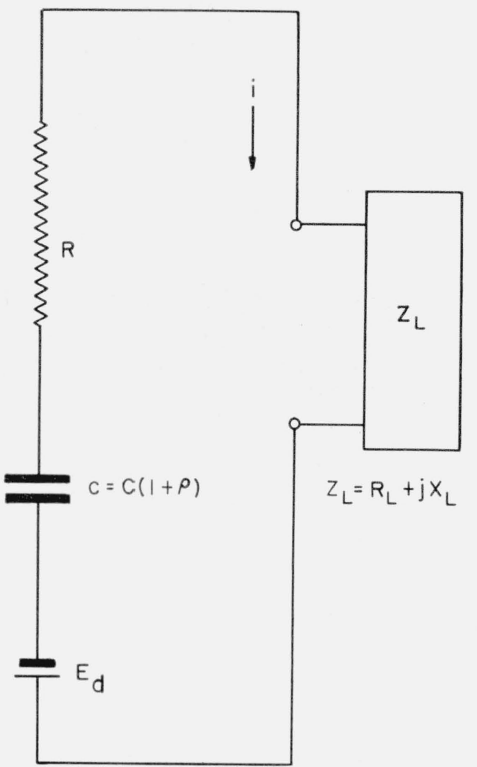

Figure 8. Equivalent circuit for analyzing the "U-effect."
From eq (6) and the definition of capacitance

$$
c=C_{0}(1+\rho a)=Q / V
$$

where $Q$ is the charge on the plates and $V$ the potential difference between the plates. Solving eq (7) for $Q$ gives

$$
Q=C_{0}(1+\rho a) V \text {. }
$$

Using Kirchoff's law

$$
V=E_{d}-i Z
$$

where $i$ is the current and $Z=R+Z_{L}$ (see fig. 8). Substituting eq (9) into eq (8) gives

$$
Q=C_{0}(1+\rho a)\left(E_{d}-i Z\right) .
$$

Differentiating eq (10) gives for the current

$$
d Q / d t=i=\frac{d}{d t} C_{0}(1+\rho a)\left(E_{d}-i Z\right) .
$$

Defining the variables $i$ and $\rho$ as

$$
\begin{aligned}
& i=I \exp (j \omega t) \\
& \rho=P \exp (j \omega t),
\end{aligned}
$$

and using these definitions in eq (11) gives, after carrying out indicated differentiation and rearranging

$$
I=\frac{P E_{d}}{R_{L}+R+j\left(X L-\frac{1}{\omega C_{0}}\right)}=\frac{V_{a c}}{R_{L}+R+j\left(X L-\frac{1}{\omega C_{0}}\right)}
$$

where $Z=R+Z_{L}=R+R_{L}+j X_{L}$ and $P E_{d}=V_{a c}$ is, so to speak, the a-c electromotive force of the "U-effect."

One notes that the "U-effect" is directly proportional to the amplitude of the periodic function. At a given frequency the $g$ force of vibration is directly proportional to the amplitude of the vibrator. Examination of table 2 reveals that proportionality between $g$ force (vibration amplitude) and $V_{a c}$ is confirmed especially at the higher frequencies where resonance effects are not predominant.

The similarity in the test cell output and the "U-effect" is noted in figure 9 where the cell output at $1 \mathrm{~g}$ force is plotted as a function of frequency together with the "U-effect" of mercury. No attempt has been made to analyze the test cell output to determine the size of the mercury drops in the cells, although the characteristics of the "U-effect" have been shown to be related to the drop size.

\subsection{Transient D-C Effects}

The change in d-c emf of the cells during the vibration studies may be the result of an intense local heating of the electrode material. However, both the a-c and d-c emf effects appeared and disappeared 


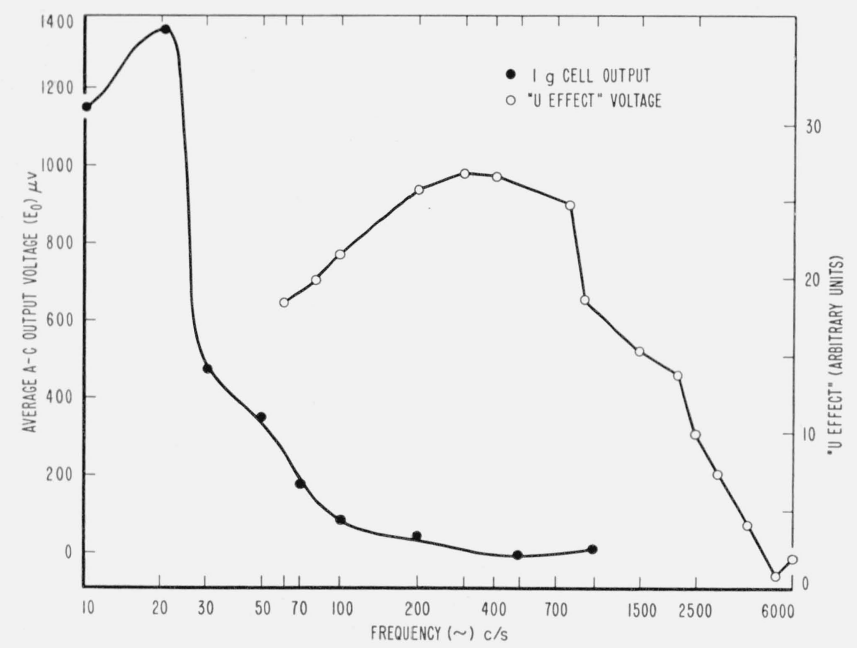

Figure 9. Variation of the a-c output with frequency at $1 \mathrm{~g}$.

instantaneously and in most cases did not exhibit a time dependence as might be expected if a heating effect were dominating the cell behavior. A more reasonable cause for the d-c emf effect resides in the properties of the electrodes which are responsible for the cell emf. A close examination of the photographs in figure 6 reveals that the output waveform may not be symmetrical, hence the average emf may not be zero. The result will be a shift in the d-c electromotive force. Unfortunately, the zero line in the photographs is not known since a-c amplifiers were used in this study.

Another source of the shift in d-c emf may be faradaic rectification. The current-potential characteristics of electrode processes are normally considered to be symmetrical about the equilibrium electrode potential. Actually, the current-potential curves are asymmetric with respect to the equilibrium potential. As a result of this asymmetry, when the electrode-solution interface is subjected to an alternating field, a slight shift from the equilibrium electrode potential will occur. The magnitude and direction of this shift is governed by the characteristic parameters of the electrode processes [3]. This shift from equilibrium potential when an electrode is subjected to an alternating field is termed faradaic rectification. Any change in cell emf due to faradaic rectification is related directly to the kinetic parameters of the two electrode reactions in the cell. The kinetics of the $\mathrm{Hg}-\mathrm{Hg}_{2}{ }^{++}$electrode have been studied by Oldham [4]. Analysis of his data reveals that the ratio of the a-c signal to the shift in the d-c emf of the electrode was about 10 . Examination of table 2 reveals that the a-c/d-c output of the test cells is almost 10. Unfortunately, similar information for the cadmium electrode is not available and a calculation of the expected faradaic rectification for the cell as a unit is not possible. Faradaic rectification may occur in both the test and reference cell. It is also possible that the $\mathrm{d}$-c shift is a result of nonequilibrium conditions in the cell.

\section{Conclusion}

A preliminary report of the effects of vibration and shock on four unsaturated standard cells has been given. The results of this investigation should apply qualitatively to unsaturated cells of other sizes, shapes, and constructions. The cells are affected by both mechanical vibration and shock as illustrated by the a-c and d-c transient effects which were observed. The transient a-c and d-c cell output depended on the magnitude of the acceleration encountered and the frequency of the vibration. The observed shift in d-c emf in the cells was within the 0.01 percent limit of precision for all frequencies at $1 \mathrm{~g}$ acceleration. For the more severe conditions at $10 \mathrm{~g}$ acceleration the a-c and d-c transient effects exceeded the 0.01 percent level of cell precision. The a-c output of the cell was large and exceeded $0.1 \mathrm{mv}$ on many occasions. The shocks were almost without effect on the d-c cell emf. The cells were within the 0.01 percent level of precision during the shock studies; indeed, the shift in d-c emf was less than $2 \mu \mathrm{v}$. However, test cell output transients during the shock study oftentimes exceeded $1 \mathrm{mv}$. After the cells were subjected to shock or vibration, the cells recovered within the 0.01 percent level of precision almost instantaneously, and the cells returned to the preshock or vibration condition in less than $3 \mathrm{~min}$. The authors were continually amazed by the ruggedness and dependability of the cells used in this study. The unsaturated standard cell did not behave as a "delicate" standard.

The observed transient effects were interpreted qualitatively using the concept of the "U-effect" and the principle of faradaic rectification. A continuation of this study to include other types of cell construction as well as the effects of cell orientation with respect to the direction of the acceleration is suggested by the authors.

The authors thank Dr. W. J. Hamer for his support and helpful suggestions during the work, and L. K. Irwin, T. Dimoff, and B. Payne of the Engineering Mechanics Section for their assistance in conducting the vibration studies.

\section{References}

[1] G. D. Vincent, Trans. IRE I-y, 221 (1958).

[2] S. Aleda, F. Tsuji, and A. Watanabe, Proc. 2nd International Congress of Surface Activity 3, 3 (1957).

[3] P. Delahay, M. Senda, and C. H. Weis, J. Am. Chem. Soc. 83, 312 (1961)

[4] K. B. Oldham, Trans. Faraday Soc. 53, 80 (1957).

(Paper 66C2-89) 